\title{
CTNNB1 Gene Mutations, Pituitary Transcription Factors, and MicroRNA Expression Involvement in the Pathogenesis of Adamantinomatous Craniopharyngiomas
}

\author{
Marina Lanciotti Campanini • Leandro Machado Colli • \\ Beatriz Maria Carvalho Paixao • Tatiana Pereira Freitas Cabral • \\ Fernando Colbari Amaral • Helio Rubens Machado • Luciano Serafin Neder • \\ Fabiano Saggioro - Ayrton Custodio Moreira - Sonir Roberto Rauber Antonini • \\ Margaret de Castro
}

Published online: 2 November 2010

(C) Springer Science+Business Media, LLC 2010

\begin{abstract}
Genes involved in formation/development of the adenohypophysis, CTNNB1 gene, and microRNAs might be implicated in the craniopharyngioma pathogenesis. The objective of this study is to perform the molecular analysis of HESX1, PROP1, POU1F1, and CTNNB1 genes and evaluate a panel of miRNA expression in craniopharyngioma. We also verified whether the presence of CTNNB1 mutation is associated with clinical findings and miRNA expression. The study included 16 patients with adamantinomatous craniopharyngioma (nine children and seven
\end{abstract}

M. L. Campanini - L. M. Colli • B. M. C. Paixao • T. P. F. Cabral •

F. C. Amaral $\cdot$ A. C. Moreira $\cdot$ M. de Castro $(\square)$

Department of Internal Medicine,

School of Medicine of Ribeirão Preto,

University of São Paulo,

Ribeirão Preto, São Paulo 14049-900, Brazil

e-mail: castrom@fmrp.usp.br

H. R. Machado

Department of Surgery and Anatomy,

School of Medicine of Ribeirão Preto,

University of São Paulo,

Ribeirão Preto, Brazil

L. S. Neder $\cdot$ F. Saggioro

Department of Pathology,

School of Medicine of Ribeirão Preto,

University of São Paulo,

Ribeirão Preto, Brazil

S. R. R. Antonini

Department of Pediatrics,

School of Medicine of Ribeirão Preto,

University of São Paulo,

Ribeirão Preto, Brazil adults; eight females and eight males; 6-55 years, median 15.5 years). DNA, RNA, and cDNA were obtained from craniopharyngioma and normal pituitaries. DNA was also extracted from peripheral blood of healthy subjects. All genes were amplified by polymerase chain reaction and direct sequenced. Relative quantification of miRNA expression was calculated using the $2^{-\Delta \Delta \mathrm{Ct}}$ method. We found no mutations in $H E S X 1, P R O P 1$, and $P O U 1 F 1$ genes and four polymorphisms in PROP1 gene which were in Hardy-Weinberg equilibrium and had similar allelic frequencies in craniopharyngioma and controls. We found seven different mutations in CTNNB1 in eight of 16 patients. Younger patients presented more frequently $C T N N B 1$ mutation than adults. We observed hyperexpression of miR-150 (1.7-fold); no different expression of miR-16-1, miR-21, and miR23a; and an underexpression of miR-141, let-7a, miR16, miR-449, miR-145, miR-143, miR-23b, miR-15a, and miR-24-2 (ranging from -7.5 to -2.5 -fold; $p=0.02$ ) in craniopharyngioma. There was no association between tumor size or the recurrence and the presence of CTNNB 1mutations. miR-16 and miR-141 were underexpressed in craniopharyngioma presenting $C T N N B 1$ mutations. miR-23a and miR24-2 were hyperexpressed in patients who underwent only one surgery. Mutations or polymorphisms in pituitary transcription factors are unlikely to contribute to the adamantinomatous craniopharyngioma pathogenesis, differently of CTNNB1 mutations. Our data suggest the potential involvement of the deregulation of miRNA expression in the craniopharyngioma pathogenesis and outcome and also that the miRNA could modulate the Wnt signaling pathway in craniopharyngioma tumorigenesis. 
Keywords Craniopharyngioma $\cdot$ Pituitary transcription factors $\cdot C T N N B 1$ gene $\cdot$ microRNA expression

\section{Introduction}

Craniopharyngiomas (CP) are benign epithelial, slow growing tumors of the sellar region. These tumors are among the most common childhood brain tumors but may be also diagnosed during adult life. Despite their benign histological appearance, they often show an unpredictable growth pattern and are frequently associated with severe adverse effects, significant morbidity, reducing quality of life and long-term survival [1]. CP pathogenesis is poorly understood. A subset of $\mathrm{CP}$ is monoclonal in origin [2]. Chromosomal imbalances are rare events in both adamantinomatous and papillary $\mathrm{CP}$ [3], although translocation, deletion, and an increase in DNA copies have been demonstrated [4]. In contrast, mutations in the p53 tumor suppressor gene [5] and the Gsp or Gip oncogenes have not been found [2].

Two hypotheses have been considered regarding the genesis of $\mathrm{CP}$, which could result from metaplasia of adenohypophyseal cells in the pituitary stalk or gland or could arise from neoplastic transformation of embryonic squamous cell rests of the involuted craniopharyngeal duct $[6,7]$. In humans, at approximately 3 weeks of gestation, the oral ectoderm invaginates to form the rudimentary pituitary primordium, the Rathke's pouch. By the end of the second month, a definitive Rathke's pouch separates from the oral ectoderm. Then, the anterior side of this pouch undergoes a period of intense proliferation and differentiation to form the anterior lobe of the pituitary gland development [8]. By birth, the anterior pituitary is comprised of five cell types that are defined by the hormone(s) they secrete. Differentiation of these cell types occurs in a temporally and spatially restricted manner. Several classes of homeodomain-containing transcription factors play important roles in both lineage specification and cell-typespecific gene expression [8]. Based on the hypothesis that CP can arise from embryonic remnants of Rathke's pouch, which is the primordium of the anterior and intermediate lobes of the pituitary gland, these transcription factors might be involved in the pathogenesis of CP.

Mutations of the glycogen synthase kinase $3 \beta$ binding domain of CTNNB1 gene have been detected in calcifying odontogenic cysts, pilomatricomas, and in adamantinomatous CP [9-12], suggesting a potential role of the associated Wnt/wingless signaling pathway during tumorigenesis of these particular neoplasms. Recently, nuclear $\beta$-catenin accumulation was shown as a highly significant finding in adamantinomatous CP [13]. As a key player of the canonical Wnt signaling pathway, $\beta$-catenin plays an important role during development cellular proliferation, differentiation, and migration [14].

MicroRNAs (miRNAs) are an abundant class of endogenous small RNA molecules that act as negative regulators of the protein-coding gene expression. miRNAs have been related to control multiple biological processes, including stem cell growth, apoptosis, and cancer [15], by regulating the expression of oncogenes and tumor suppressor genes [16]. Several deregulated miRNAs have been involved not only in pituitary cell proliferation and apoptosis, but also in neoplastic transformation [17]. There are few studies on miRNAs in pituitary tumors demonstrating underexpression of miR-15a and miR-16 in growth hormone (GH)- and PRL-secreting pituitary adenomas and underexpression of miR-145, miR-21, miR-141, let-7a, miR-150, miR-15a, miR-16, and miR-143 in adrenocorticotropic hormone (ACTH)-secreting pituitary tumors [18, 19]. miR-15a and miR-16 were inversely correlated with tumor diameter and directly correlated with secretion of the anti-neoplastic cytokine p43 [20], and patients with ACTH-secreting pituitary tumors presenting lower miR-141 expression showed better chance of remission [19]. Recently, it was proposed that miRNAs potentially activate Wnt signaling pathways, suggesting that miRNAs via Wnt might be involved in the tumor formation [21]. There are lacking studies on miRNA expression in CP.

In the present study, we performed the molecular analysis of three homeodomain-containing transcription factors, HESX1, PROP1, and POU1F1, and the CTNNBlgene as well as the evaluation of a panel of miRNA expression in adamantinomatous $\mathrm{CP}$ in order to elucidate their contribution to the tumorigenesis. In addition, we also verified whether the presence of CTNNB1 mutations is associated with age of diagnosis, tumor size, recurrence, or different miRNA expression.

\section{Subjects and Methods}

\section{Patients and Clinical Assessment}

This study was approved by the Institutional Review Board for Human Research of the University Hospital of School of Medicine of Ribeirão Preto-University of São Paulo and informed consent was obtained from all subjects (process no. 1188/2009). We evaluated sixteen Brazilian patients with CP (eight males and eight females; aged 6 to 55 years, median of 15.5 years, being nine children and seven adults). Clinical criteria for the diagnosis of CP included neurological, endocrinological, and radiological findings as well as histological examinations of tissue specimens in all cases.

All patients underwent biochemical evaluation to confirm the diagnosis of hypothalamic and pituitary abnormalities, as 
previously described [22]. Hypothyroidism was diagnosed by basal values of $\mathrm{FT}_{4}$ and TSH according to the normal age matched values provided by the manufacturer. On the other hand, adrenal, GH, and gonadotrophic deficiencies were confirmed by dynamic tests. To evaluate the adrenal axis, we performed insulin tolerance test (ITT) (normal response: plasma cortisol $>19 \mu \mathrm{g} / \mathrm{dl}$ ). The $\mathrm{GH}$ axis was evaluated by two different dynamic tests, e.g., ITT and L-dopa tests, after priming with estrogen. Glucagon test was used instead of ITT when patients presented seizures (normal response: GH peak $>7 \mathrm{ng} / \mathrm{ml}$ ). Hypogonadism was diagnosed by gonadotropin-releasing hormone test, when patients were in an appropriate chronological and bone ages (normal response: $\mathrm{LH}>6.8 \mathrm{mUI} / \mathrm{ml}$ ). To confirm the vasopressin deficiency, serum sodium and plasma and urinary osmolality were determined by flame photometry and freezing depression point, respectively, in basal condition or after the water deprivation test, with or without desmopressin administration. Obesity was diagnosed through the body mass index and classified according to the WHO classification. The hormone levels were assessed by the age, sex, and pubertal stages.

Subjects were evaluated by magnetic resonance image (MRI) performed with a 1.5-T imager (Siemens Vision) with a head coil. All patients were submitted to ophthalmologic evaluation by an expertise.

\section{Molecular Studies}

Total DNA and RNA were extracted, using TRIzol reagent (Invitrogen Life Technologies, Inc., Carlsbad, CA), from 16 craniopharyngioma tumoral tissues obtained during surgery from 2005 to 2008. In addition, 15 normal anterior pituitaries, obtained during autopsies from subjects (mean age, 53 years old; ranging from 36 to 76 years old) who had natural death without previous evidence of any endocrine disease or neurological abnormality, were used as control. Tumoral samples were microdissected by an experienced pathologist in order to separate any non-tumoral tissue. Part of the tumor tissue was processed for routine histopathological examination, and other stored at $-70^{\circ} \mathrm{C}$.

DNA extraction and purification from fresh frozen CP and normal pituitary tissues were performed as previously described [19]. The coding regions and intron/exon boundaries of POU1F-1, PROP1, HESX1, and the GSK$3 \beta$-phosphorylation sites of the CTNNB1 genes were amplified by polymerase chain reaction (PCR) using primers previously published [23-25]. Genomic DNAs from all patients and from 71 healthy Brazilian subjects were sequenced to investigate the presence of mutations in POU1F1, PROP1, HESX1, and CTNNB1 genes. In addition, reverse transcriptase PCR from normal pituitary and tumoral tissues were performed using a first strand cDNA synthesis kit (Taqman RT reagents, Applied Biosystems, Branchburg, New Jersey, USA). PCR amplifications from cDNA product were performed using a specific pair of primers also encompassing the GSK-3 $\beta$-phosphorylation sites of the CTNNB1 gene (5'GCTGATTTGATGGAGTTGGA/3' GCTACTTGTTCTTGAGTGAA). All PCR products from peripheral blood, tumoral DNA, and cDNA were purified and direct sequenced from both directions on an ABI PRISM 310 autosequencer (Applied Biosystems, Foster City, CA).

The sequences of HESX1, POU1F1, PROP1, and $C T N N B 1$ genes, obtained from each subject, were compared to sequences obtained from Ensembl Gene Report (ENSG00000163666, EN S G00000064835, ENSG00000175325, and ENSG00000168036, respectively).

\section{microRNA Expression Profiling}

Identification of potential miRNA target molecules was performed using TargetScan 5.1 (http://www.targetscan. org), miRNAMap 2.0 (http://mirnamap.mbc.nctu.edu/), and miRGene (http://diana.pcbi.upenn.edu/miRGene) databases. The outputs of these databases were merged, and all potential targets of a miRNA predicted. Besides let- $7 \mathrm{a}$, miR-15a, miR-16, miR-23a, miR-23b, miR-24-2, miR-150, and miR-449, which direct targeting the $\mathrm{Wnt} / \beta$-catenin, we also evaluated miR-16-1, miR-21, miR-141, miR-143, and miR-145 expression, using qPCR. Primers and probe mix of the TaqMan ${ }^{\circledR}$ MicroRNA Assay for each miRNA and endogenous controls (RNU44 and RNU49) were also purchased from Applied Biosystems (Foster City, CA, USA). The cycle threshold (Ct) data were performed using default threshold settings. Data were presented as the mean CT for duplicates of each sample of each miRNA normalized by the endogenous controls Ct-median expression and calibrated by $\Delta \mathrm{Ct}$-median value obtained from all normal pituitary tissues. Relative quantification of miRNA expression was calculated using the $2^{-\Delta \Delta \mathrm{Ct}}$ method. Fold change of the expression of miRNAs observed in CP in relation to normal pituitaries was determined by the median of $2^{-\Delta \Delta \mathrm{Ct}}$ values of $\mathrm{CP}$ related to median of $2^{-\Delta \Delta \mathrm{Ct}}$ values of normal pituitaries.

\section{Statistical Analysis}

The expression of miRNAs in CP and normal pituitary are presented as mean, standard error deviation, median, and range. Statistics were carried out using Mann-Whitney test for continuous variables. To analyze whether the presence of CTNNB1 mutations is associated with age of the diagnosis, tumor size $(\leq 3$ or $>3 \mathrm{~cm})$, recurrence, or different miRNA expression, we used Fisher's exact test. Data were analyzed by GraphPad Prism5 software. Differences were considered significant at $p<0.05$. 


\section{Results}

\section{Clinical Assessment}

Table 1 shows the clinical and endocrine findings of patients with craniopharyngioma at the time of the diagnosis. Endocrine disorders were found in 12 patients $(12 / 16)$. Eight patients presented more than one hormone deficiency. Hypothalamic dysfunctions, such as hyperphagia and/or obesity, were observed in eight patients and weight loss in two; somnolence was observed in five patients. Neurological manifestations were observed in 12 patients; the main complaints were headache and central nervous system hypertension. Thirteen out of $16 \mathrm{CF}$ patients had either unilateral or bilateral visual disturbances. The most frequent visual defect was temporal hemianopsia; however, amaurosis was observed in two patients and papilloedema in another two. In two children, the visual field defect was not possible to be determined.

Fifteen patients were assessed by MRI and one by CT (Table 2). The tumor size varied from 1.5 to $6.5 \mathrm{~cm}(X \pm \mathrm{SD}$ : $4.4 \pm 1.4 \mathrm{~cm}$; median, $4.4 \mathrm{~cm})$. All tumors presented invasion of surrounding structures, nine showed parasellar and seven suprasellar extensions. Calcification was observed in $87.5 \%$ of the patients; tumors were solid-cystic in $62.5 \%$, solid in $31.3 \%$ and one was cystic (6.2\%). Hydrocephaly was observed in three patients and hemorrhage in $12.5 \%$. Surgical management was undertaken in all cases, and the decision to perform a complete or a partial resection was made by the neurosurgeon during the operation according to the anatomical findings. All patients were operated by the same surgeon (H.R.M.). The surgical approach was chosen based on the image findings. The transsphenoidal route was performed in $25 \%$ of surgical cases, while the remaining patients $(75 \%)$ were treated by the transcranial approach (Table 2). Gross total removal was defined as the absence of residual tumor in post-operative imaging. Partial removal was based on the detection of residual tumor post-operatively and/or on the neurosurgeon's report confirming incomplete excision. Postoperative imaging confirmed total resection in $56.2 \%$ and partial in $43.8 \%$ (Table 2). Among seven patients with residual tumor, four $(57.1 \%)$ underwent at least a second surgery. However, recurrence was also detected in two patients $(12.5 \%)$ who had total resection. The referral for radiotherapy (conventional fractionated external beam irradiation) was indicated in $18.8 \%$. The follow-up period ( $X \pm \mathrm{SD}$; $2.9 \pm 4.0$ years) ranged from $0.5-17$ years, median of 1.9 years.

There was no recovery of pre-existing pituitary hormone deficiencies after any surgical intervention; all the 16 patients required post-operative hormonal replacement therapy. By the time of the last evaluation, 15 patients were receiving desmopressin and cortisol; ten of them were receiving also levothyroxine; eight patients were diagnosed

Table 1 Clinical manifestation of patients with craniopharyngioma at the diagnosis

\begin{tabular}{|c|c|c|c|c|c|c|}
\hline Patients & Sex & $\begin{array}{l}\text { Age at the } \\
\text { diagnosis (years) }\end{array}$ & $\begin{array}{l}\text { Endocrine } \\
\text { involvement }\end{array}$ & $\begin{array}{l}\text { Hypothalamic } \\
\text { dysfunctions }\end{array}$ & $\begin{array}{l}\text { Neurological } \\
\text { manifestations }\end{array}$ & $\begin{array}{l}\text { Visual } \\
\text { disturbances }\end{array}$ \\
\hline 1 & M & 6 & Hyperprolactinemia & Somnolence & Headache & Diplopia \\
\hline 2 & M & 6 & GHD & OB & Headache, nausea/vomit & Visual deterioration \\
\hline 3 & $\mathrm{~F}$ & 7 & GHD & Weight loss & Headache, nausea/vomit & TQ RE \\
\hline 4 & $\mathrm{~F}$ & 15 & $\mathrm{GHD}, \mathrm{HG}, \mathrm{HC}$ & Somnolence & Headache, nausea/vomit & $\begin{array}{l}\text { Papilloedema, optic } \\
\text { atrophy LE, BH }\end{array}$ \\
\hline 5 & $\mathrm{~F}$ & 8 & No & $\begin{array}{l}\text { Hyperphagia, OB, } \\
\text { somnolence }\end{array}$ & $\begin{array}{l}\text { Headache, hemiparesis, } \\
\text { ptosis LE }\end{array}$ & $\mathrm{AM}$ \\
\hline 6 & M & 9 & $\begin{array}{l}\text { GHD, HC, } \\
\text { hyperprolactinemia }\end{array}$ & Somnolence & Headache, nausea/vomit & AM LE/TH RE \\
\hline 7 & $\mathrm{~F}$ & 10 & DI & OB & Headache & Papilloedema, TH LE \\
\hline 8 & M & 14 & No & OB & Headache & $\mathrm{BH}$ \\
\hline 9 & M & 16 & GHD, DI, HT, HG, HC & & - & - \\
\hline 10 & M & 20 & No & OB & - & $\mathrm{BH}$ \\
\hline 11 & $\mathrm{~F}$ & 21 & $\begin{array}{l}\text { DI, HT, HG, HC, } \\
\text { hyperprolactinemia }\end{array}$ & - & Headache, nausea/vomit & $\mathrm{BH}$ \\
\hline 12 & $\mathrm{~F}$ & 22 & GHD, HT, HG, HC & OB & Headache & $\mathrm{BH}$ \\
\hline 13 & M & 26 & GHD, DI, HT, HG, HC & OB & - & - \\
\hline 14 & $\mathrm{~F}$ & 27 & DI, HG, HC & Somnolence & Nausea/vomit & - \\
\hline 15 & M & 30 & $\mathrm{HT}, \mathrm{HG}, \mathrm{HC}$ & $\begin{array}{l}\text { Hyperphagia, OB, } \\
\text { somnolence }\end{array}$ & Headache & Diplopia \\
\hline 16 & $\mathrm{~F}$ & 55 & No & Weight loss & - & TQ LE \\
\hline
\end{tabular}

$M$ male, $F$ female, $D I$ diabetes insipidus, $G H D$ growth hormone deficiency, $H T$ hypothyroidism, $H G$ hypogonadism, $H C$ hypocortisolism, $O B$ obesity, $L E$ left eye, $R E$ right eye, $B H$ bitemporal hemianopsia, $A M$ amaurosis, $T H$ temporal hemianopsia, $T Q$ temporal quadranopsia 
Table 2 Individual characteristics of imaging, extension of the disease, modality of therapy, follow-up, and mutational analysis of CTNNB1 in patients with adamantinomatous craniopharyngioma

\begin{tabular}{|c|c|c|c|c|c|c|c|c|c|}
\hline Patient & $\begin{array}{l}\text { CT or } \\
\text { MRI }\end{array}$ & $\begin{array}{l}\text { Tumor } \\
\text { size }(\mathrm{cm})\end{array}$ & $\begin{array}{l}\text { Extension } \\
\text { of disease }\end{array}$ & Treatment & Tumor characteristics & CNS involvement & $\begin{array}{l}\text { Follow-up } \\
\text { (years, months) }\end{array}$ & $\begin{array}{l}\text { Nucleotide } \\
\text { change }\end{array}$ & $\begin{array}{l}\text { Effect of } \\
\text { mutation }\end{array}$ \\
\hline 1 & MRI & 6.0 & PS & $\mathrm{TC} / \mathrm{PR}$ & Calcification, solid-cystic & $\begin{array}{l}\text { Invasion 3rd ventricle, } \\
\text { hydrocephaly }\end{array}$ & 1 month & $\begin{array}{c}\mathrm{TCT} \rightarrow \mathrm{TTT} \\
(\mathrm{c} .98 \mathrm{C}>\mathrm{T})\end{array}$ & p.Ser33Phe \\
\hline 2 & MRI & 3.1 & PS & $\mathrm{TC} / \mathrm{PR}$ & Calcification, solid-cystic & $\begin{array}{l}\text { Hypothalamic and OQ } \\
\text { compression, invasion } \\
\text { 3rd ventricle }\end{array}$ & 2 years & $\begin{array}{l}\mathrm{ACC} \rightarrow \mathrm{GCC} \\
\quad(\mathrm{c} .121 \mathrm{~A}>\mathrm{G})\end{array}$ & p.Thr41Ala \\
\hline 3 & MRI & 4.7 & PS & $\mathrm{TC} / \mathrm{PR}$ & Calcification, cystic & None & 1 year and 7 months & $\begin{array}{r}\mathrm{ACC} \rightarrow \mathrm{ATC} \\
(\mathrm{c} .121 \mathrm{C}>\mathrm{T})\end{array}$ & p.Thr41Ile \\
\hline 4 & MRI & 4.4 & SS & TSS/TR & Calcification, solid & $\begin{array}{l}\text { ON/OQ compression, } \\
\text { Hydrocephaly }\end{array}$ & 1 year & No & \\
\hline 5 & MRI & 6.2 & PS & $\mathrm{TC} / \mathrm{PR}$ & Calcification, solid & None & 1 year & $\begin{array}{c}\mathrm{TCT} \rightarrow \mathrm{TGT} \\
(\mathrm{c} .98 \mathrm{C}>\mathrm{G})\end{array}$ & p.Ser33Cys \\
\hline 6 & MRI & 6.5 & SS & $\begin{array}{l}\text { TC+RTX/ } \\
\text { TR }\end{array}$ & Solid-cystic & 3rd cranial nerve palsy & 1 year and 3 months & $\begin{array}{l}\mathrm{GAC} \rightarrow \mathrm{AAC} \\
\quad(\mathrm{c} .94 \mathrm{G}>\mathrm{C})\end{array}$ & Asp32Phe \\
\hline 7 & MRI & 5.0 & PS & $\begin{array}{l}\text { TC+RTX/ } \\
\text { PR }\end{array}$ & Calcification, solid-cystic & Invasion 3rd ventricle & $\begin{array}{l}1 \text { year and } \\
4 \text { months }\end{array}$ & No & \\
\hline 8 & MRI & 2.5 & PS & $\mathrm{TC} / \mathrm{TR}$ & Solid & $\begin{array}{l}\text { OQ compression, } \\
\text { invasion } 3 \text { rd ventricle }\end{array}$ & 4 years & $\begin{array}{r}\mathrm{TCT} \rightarrow \mathrm{TGT} \\
(\mathrm{c} .110 \mathrm{C}>\mathrm{G})\end{array}$ & p.Ser37Cys \\
\hline 9 & MRI & 1.5 & PS & TSS/TR & Calcification, solid-cystic & $\begin{array}{l}\text { Hypothalamic and } \mathrm{OQ} \\
\text { compression, hemorrhage }\end{array}$ & 9 months & $\begin{array}{r}\mathrm{TCT} \rightarrow \mathrm{TGT} \\
\quad(\mathrm{c} .110 \mathrm{C}>\mathrm{G})\end{array}$ & p.Ser37Cys \\
\hline 10 & MRI & 6.5 & SS & $\mathrm{TC} / \mathrm{PR}$ & Calcification, solid & OQ compression & 3 years & No & \\
\hline 11 & MRI & 4.0 & SS & $\mathrm{TC} / \mathrm{TR}$ & Calcification, solid-cystic & $\begin{array}{l}\text { Hypothalamic and OQ } \\
\text { compression }\end{array}$ & 7 years & No & \\
\hline 12 & MRI & 4.2 & PS & TSS/TR & Calcification, solid-cystic & $\begin{array}{l}\text { Hypothalamic and } \mathrm{OQ} \\
\text { compression, hemorrhage }\end{array}$ & 1 year & No & \\
\hline 13 & MRI & 2.5 & SS & TSS/TR & Calcification, solid-cystic & Hydrocephaly & 7 months & No & \\
\hline 14 & MRI & 4.8 & PS & $\mathrm{TC} / \mathrm{TR}$ & Calcification, solid-cystic & $\begin{array}{l}\text { Hypothalamic and OQ } \\
\text { compression }\end{array}$ & 1 year and 10 months & $\begin{array}{l}\mathrm{GGA} \rightarrow \mathrm{GAA} \\
\quad(\text { c. } 101 \mathrm{G}>\mathrm{A})\end{array}$ & p.Gly34Glu \\
\hline 15 & CT & 3.2 & SS & $\begin{array}{l}\text { TC+RTX/ } \\
\text { PR }\end{array}$ & Calcification, solid & None & 16 years & No & \\
\hline 16 & MRI & 2.5 & SS & $\mathrm{TC} / \mathrm{PR}$ & Calcification, solid-cystic & None & 2 years and 6 months & No & \\
\hline
\end{tabular}

$C T$ computerized tomography, $S S$ suprasellar extension, $P S$ parasellar extension, $C N S$ central nervous system, $O Q$ optic chiasm, $O N$ optic nerve, $T C$ transcranial surgery, TSS transsphenoidal surgery, $R T X$ radiotherapy, $T R$ total surgical removal, $P R$ partial surgical removal

as having hypogonadism. GH replacement was given to six patients (four children and two young adults). Obesity was observed in nine patients and hyperfagia in three patients. Post-operative visual function was maintained in two patients, improved in six, and deteriorated in two patients. All patients showed histological characteristics of an adamantinomatous $\mathrm{CP}$.

\section{Genetic Analysis}

In tumoral DNA as well as in cDNA obtained from $\mathrm{CP}$ tissues, we found seven different mutations in the CTNNB1 gene (Table 2) in eight patients with CP. Six of them have been previously described: the $\mathrm{g} .304 \mathrm{G}>\mathrm{A}$, corresponding to c. $94 \mathrm{G}>\mathrm{A}$ at codon 32 (p. $\mathrm{N} 32 \mathrm{~F}$ ); the g. 308C $>\mathrm{G}$, corresponding to c. $98 \mathrm{C}>\mathrm{G}$ at codon 33 (p.S33C); the g.308C $>$ T, corresponding to c. $98 \mathrm{C}>\mathrm{T}$ at codon 33 (p.S33F); the g. $320 \mathrm{C}>\mathrm{G}$, corresponding to $\mathrm{c} .110 \mathrm{C}>\mathrm{G}$ at codon 37 (p.S37C) in two patient; the g.331A $>\mathrm{G}$, corresponding to c. $121 \mathrm{~A}>\mathrm{G}$ at codon 41 (p.T41A); and the g.332C $>\mathrm{T}$, corresponding to c.122C $>\mathrm{T}$ at codon 41 (p.T41I). We also found one new mutation: the g. $311 \mathrm{G}>\mathrm{A}$, corresponding to c. $101 \mathrm{G}>\mathrm{A}$ at codon 34 (p.G34E). We found no $C T N N B 1$ gene mutation in genomic DNA obtained from CP patients or in the subset of general Brazilian controls. We also did not find any CTNNB1 gene mutation in the DNA or cDNA obtained from 15 normal pituitaries. We observed that patients younger than 18 years old presented more frequently CTNNB1 mutation (seven of nine patients) than adults (one of seven) $(p=0.01)$. On the other hand, there was no association between tumor size or the recurrence of the disease and the presence of $C T N N B 1$ mutation.

No mutations were identified in $H E S X 1, P O U 1 F 1$, and $P R O P 1$ genes. However, in tumoral DNA from $\mathrm{CP}$ and in genomic DNA from controls, we found four single nucleotide polymorphisms (SNPs) in PROP1 gene (Table 3). Allelic frequencies of each polymorphism were assessed in DNA from CP tissue and compared to genomic DNA from a subset of the normal Brazilian population. All polymorphisms were in the Hardy-Weinberg equilibrium, and allelic frequencies were similar in CP and genomic DNA from control subjects. 
Table 3 PROP1 SNPs in craniopharyngiomas

\begin{tabular}{lllll}
\hline SNP & Genotype & Patients (\%) & Controls (\%) & $p$ \\
\hline p.A9A & CC & 13 & 28 & ns \\
$($ rs1135320) & CT & 60 & 41 & \\
& TT & 27 & 31 & \\
IVS1+3G>A & GG & 27 & 31 & ns \\
$($ rs4072924) & AG & 53 & 38 & \\
& AA & 20 & 31 & \\
p.A142T & GG & 64 & 60 & \\
$($ rs1800197) & GA & 36 & 36 & \\
& AA & - & 4 & \\
p.S20N & GG & 100 & 100 & \\
$($ rs7445271) & & & & \\
\hline
\end{tabular}

$n s$ not significant

microRNA Expression Profiling

Table 4 shows the relative expression of a panel of miRNA in $\mathrm{CP}$ and normal pituitaries. Expression of nine microRNAs (miR-141, let-7a, miR-16, miR-449, miR-145, miR143, miR-23b, miR-15a, and miR-24-2) was significantly lower in CP than in normal pituitaries. miR-150 was found to be overexpressed in $\mathrm{CP}$ while no differential expression was found in miR-16-1, miR-21, and miR-23a. Considering the age of the patients, there was no difference in the expression pattern of the examined microRNAs between children and adults. Considering the presence or absence of CTNNB1 mutations, miR-16 was underexpressed in $\mathrm{CP}$ presenting $C T N N B 1$ mutation $(p=0.03)$, and there was a tendency $(p=0.06)$ to lower expression of miR-141 in tumoral tissues (Fig. 1a, b). We observed that six out of eight patients $(75 \%)$ with $\mathrm{CP}$ without mutation presented both miR-16 and miR-141 upregulated. In addition, in the other two patients, at least one of these miRNAs was upregulated. miR-23a and miR24-2 were more expressed $(p=0.04)$ in patients with CP who underwent only one surgery than $\mathrm{CP}$ patients with two or more surgeries (Fig. 1c, d).

\section{Discussion}

In the present study, we reviewed the clinical manifestations of patients with adamantinomatous $\mathrm{CP}$, by the time of the diagnosis, and performed the molecular analysis of HESX1, PROP1, POU1F1, and CTNNB1 genes in order to elucidate their contribution to the tumorigenesis. We found that mutations or polymorphisms in pituitary transcription factors or their co-regulators are unlikely to contribute to the pathogenesis of $\mathrm{CP}$. On the other hand, we reinforced that somatic CTNNB1 gene mutations are related to the pathogenesis of adamantinomatous $\mathrm{CP}$, mainly in children. We also demonstrated, for the first time, abnormal expression of a panel of microRNAs, including hyperexpression of miR-150 and underexpression of let-7a, miR16, miR-15a, miR-23b, miR-24-2, miR-141, miR-143, miR-145, and miR-449 in adamantinomatous CP. Our data suggest that these small molecules can inhibit the Wnt signaling via interaction with different compounds of the Wnt pathway.

Endocrine as well as neurological disorders were found in the majority of patients. Three or more hormone deficiencies occurred in $62.5 \%$, which is in agreement to the reported frequencies $(54-100 \%)$ in previous studies [1, 26, 27]. Headache, central nervous system hypertension, and visual disturbances were observed in most patients probably due to the proximity to and the subsequent

Table 4 miRNA expression in craniopharyngiomas compared to normal pituitary tissues

\begin{tabular}{|c|c|c|c|c|c|}
\hline miRNA & Mean $\Delta \mathrm{Ct}$ normal & Mean $\Delta \mathrm{Ct}$ tumor & Normal mean $2^{-\Delta \Delta \mathrm{Ct}} \cdot$ median range & Tumor mean $2^{-\Delta \Delta \mathrm{Ct}} \cdot$ median range & Fold tumor/normal \\
\hline $\operatorname{miR}-150$ & $-1.7 \pm 1.9$ & $-4.5 \pm 2.2$ & $1.3 \pm 1.2 ; 1.0(0.02-4.6)$ & $12.6 \pm 17.3 ; 8.1(0.3-66.5)$ & $1.7(p=0.01)$ \\
\hline miR-16-1 & $3.4 \pm 1.5$ & $4.2 \pm 1.9$ & $1.5 \pm 1.3 ; 1.0(0.1-4.8)$ & $1.5 \pm 1.4 ; 0.7(0.04-4.4)$ & ns \\
\hline $\operatorname{miR}-21$ & $-6.4 \pm 1.4$ & $-6.9 \pm 1.7$ & $1.4 \pm 1.4 ; 1.0(0.2-4.7)$ & $2.8 \pm 4.9 ; 1.7(0.2-20.7)$ & ns \\
\hline $\operatorname{miR}-23 a$ & $-1.3 \pm 0.6$ & $-1.6 \pm 1.6$ & $1.0 \pm 0.4 ; 1.0(0.5-1.8)$ & $1.9 \pm 2.1 ; 1.5(0.2-8.1)$ & ns \\
\hline $\operatorname{miR}-141$ & $-4.5 \pm 1.1$ & $-1.3 \pm 2.8$ & $1.4 \pm 0.8 ; 1.0(0.2-2.7)$ & $0.3 \pm 0.43 ; 0.1(0-1.5)$ & $-7.5(p<0.0001)$ \\
\hline let7a & $-8.2 \pm 1.8$ & $-4.8 \pm 1.9$ & $1.7 \pm 1.7 ; 1(0.5-6.7)$ & $0.2 \pm 0.3 ; 0.1(0.01-0.9)$ & $-7.4(p<0.001)$ \\
\hline miR-16 & $-9.7 \pm 1.0$ & $-6.7 \pm 1.9$ & $1.2 \pm 0.9 ; 1.0(0.2-4.2)$ & $0.2 \pm 0.2 ; 0.1(0-0.9)$ & $-7.2(p<0.0001)$ \\
\hline miR-449 & $4.3 \pm 0.6$ & $5.9 \pm 2.6$ & $1.0 \pm 0.4 ; 1.0(0.4-1.8)$ & $1.8 \pm 4.3 ; 0.2(0.03-16.3)$ & $-6.6(p=0.007)$ \\
\hline miR-145 & $-1.1 \pm 1.1$ & $1.6 \pm 2.7$ & $1.2 \pm 1.3 ; 1.0(0.2-5.5)$ & $0.5 \pm 0.8 ; 0.19(0-3.3)$ & $-5.4(p=0.002)$ \\
\hline miR-143 & $-1.3 \pm 0.8$ & $0.4 \pm 2.0$ & $1.3 \pm 0.7 ; 1.0(0.4-2.9)$ & $1.0 \pm 1.8 ; 0.26(0.05-7.4)$ & $-3.8(p=0.01)$ \\
\hline $\operatorname{miR}-23 b$ & $-5.7 \pm 0.6$ & $-4.6 \pm 1.5$ & $1.0 \pm 0.4 ; 1.0(0.4-1.6)$ & $0.8 \pm 0.9 ; 0.31(0.1-3.2)$ & $-3.2(p=0.02)$ \\
\hline miR-15a & $-1.4 \pm 0.8$ & $0.1 \pm 1.5$ & $1.0 \pm 0.5 ; 1.0(0.3-2.1)$ & $0.6 \pm 0.6 ; 0.39(0.04-2.1)$ & $-2.5(p=0.009$ \\
\hline $\operatorname{miR} 24-2$ & $2.6 \pm 0.6$ & $4.2 \pm 2.6$ & $1.2 \pm 0.5 ; 1.0(0.4-2.2)$ & $0.8 \pm 1.1 ; 0.4(0-4.3)$ & $-2.5(p=0.01)$ \\
\hline
\end{tabular}

$n s$ not significant 
Fig. 1 miRNA relative expression in craniopharyngiomas. a, b miR-16 and miR-141 expression in craniopharyngiomas with or without $C T N N B 1$ mutation. c, d miR-23a and miR-24-2 expression in craniopharyngiomas from patients who underwent one or more than one surgery
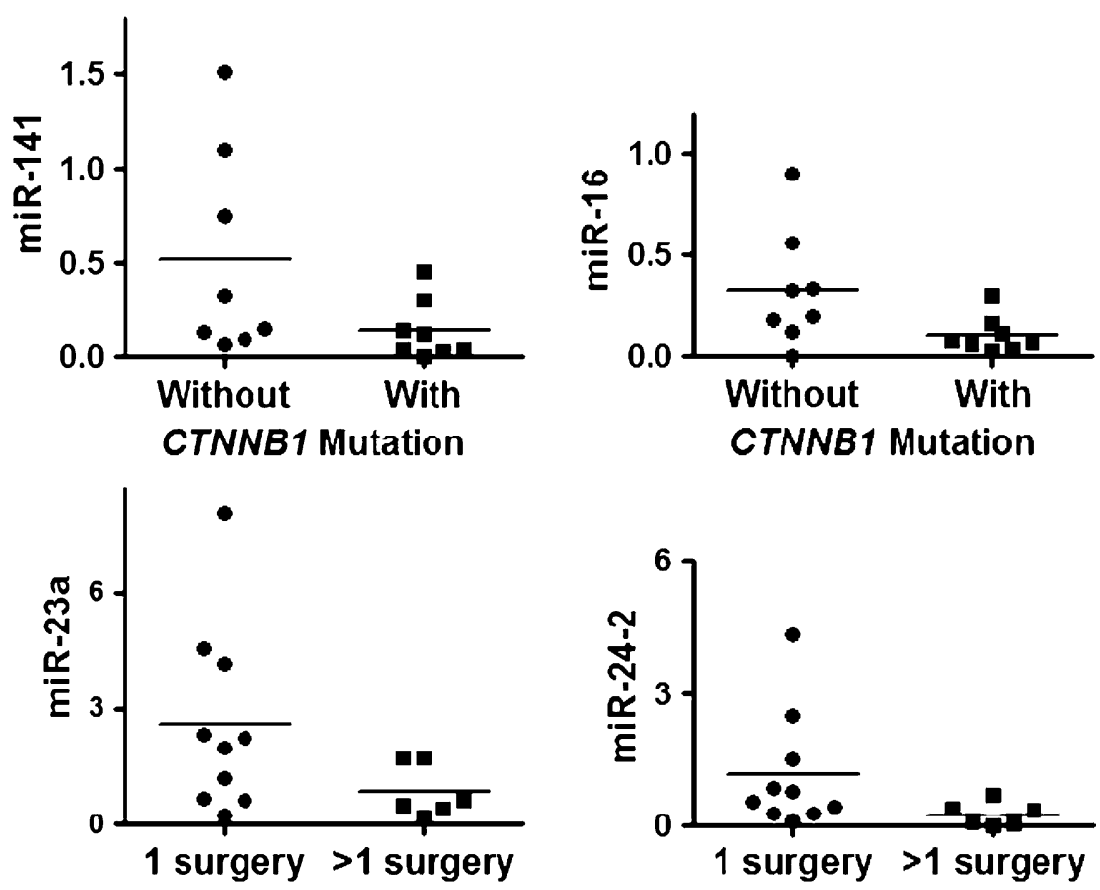

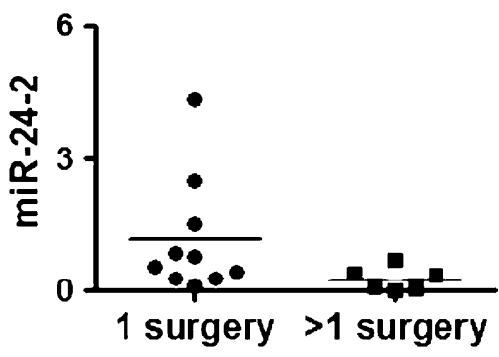

pressure effects of tumor on vital structures of the brain [1, $26,27]$. The invasion and compression of surrounding structures are due to the large tumor size observed in CP. Some reports demonstrated the average in macroscopic specimens of $3.5 \mathrm{~cm}$ at the time of initial surgery $[1,28]$; in our series, the median tumor size was $4.4 \mathrm{~cm}$, suggesting a delay in the diagnosis. Hyperphagia and obesity are the most distressing manifestations of hypothalamic injury and were observed in $50 \%$ of the patients before surgery $[1,27$, 29]. Lesion in the pituitary-hypothalamic region has the potential to affect the autonomous nervous system output from the brain influencing gut hormone secretion, so critical for controlling energy homeostasis and food intake. After treatment, there was a slight increment (62.5\%) of the number of patients presenting obesity/hyperphagia, which could be exacerbated by unmodulated hunger, reduced physical activity, and increased daytime sleepiness. Indeed, important somnolence was observed in five patients of our series. Recently, it has been demonstrated a blunted postmeal-related changes of PYY and ghrelin in obese CP compared to obese controls [30]. Hyperinsulinemia and decreased insulin sensitivity seem to be important contributing factors for observed gut hormonal changes in $\mathrm{CP}$ patient [30].

Surgical management, mainly transcranial approach, was undertaken in the majority of our patients, similarly to others [1, 31]. In our series, total resection (TR) was achieved in $56.3 \%$ of the patients, and a recurrence rate was of $22.2 \%$ while partial resection showed a recurrence rate of $57.1 \%$; both rates of recurrence are in accordance with recurrence rates in the literature $(\mathrm{TR}=0-62 \%$ and $\mathrm{PR}=25-$
$100 \%$ ) at 10-year follow-up [1, 26, 31]. In the present study, $37.5 \%$ of the patients underwent a second or even a third surgery. Radiotherapy, which has a limited value in CP [1], was performed in about $20 \%$. Hypopituitarism and diabetes insipidus occurred both in $93.8 \%$ of the patients in post-operative period. In fact, there was no recovery of preexisting pituitary hormone deficiencies after surgical intervention. All patients showed histological characteristics of an adamantinomatous CP, which is the most common type [9] and has a broader age distribution with a predilection for childhood and early adolescence [1, 28, 32].

Pituitary transcription factors involved in formation and/ or development of the adenohypophysis might be implicated in CP pathogenesis. Therefore, in the present study, we performed the molecular analysis of three homeodomaincontaining transcription factors, $H E S X 1, P R O P 1$, and $P O U 1 F 1$, involved in anterior lobe of the pituitary gland development, and the CTNNB1 gene, a co-regulator for transcription activity of PROP1 [33]. Among all these genes, PROP1 may be a commitment factor, since it is initially expressed in the dorsal pouch and developing anterior pituitary where the somatolactotrophs and definitive thyrotrophs will eventually appear [33, 34]. Further, PROP1 is required for expression of $P O U 1 F 1$, which itself is necessary for differentiation of the same lineages [35, 36]. For instance, PROP1 is known to extinguish gene expression of HESX1 [37]. No mutations were identified in HESX1, PROP1, and POU1F1 genes in CP. SNPs in PROP1 gene are also unlikely to contribute to $\mathrm{CP}$ formation. Of interest, sellar masses have been described in association with inactivating PROP-1 mutations that 
generate nonfunctional proteins, which fail to induce normal development of pituitary cells $[38,39]$, leading to hyperplasia of the adenohypophysis, cystic pituitary masses mimicking CP, or Rathke's cleft cysts [38, 39]. These findings would suggest a direct involvement of these transcription factors in the pathogenesis of CP. However, our data did not indicate that mutation or SNPs in these pituitary transcription factors, involved in Rathke's pouch and anterior pituitary development, might contribute to the adamantinomatous CP pathogenesis.

During pituitary development, Wnt/ $\beta$-catenin pathway provides a key signal for determining cell lineages, with direct interactions between $\beta$-catenin and the tissue-specific homeodomain factor Prop1, rather than lymphoid enhancerbinding factor $1 / \mathrm{T}$ cell-specific transcription factor, serving as the mechanism for transcriptional activation of the POU1F1 gene. A Prop $1 / \beta$-catenin complex simultaneously represses expression of the Hesx 1 paired-like homeodomain factor via recruitment of a series of corepressors, including HDACs 1/2, Reptin, and Groucho/TLEs [40]. These results establish a transcriptional switching mechanism for $\beta$-catenin control of cell-fate determination [33]. We found seven different mutations in CTNNB1 gene, including the novel p. Gly34Glu mutation, in $50 \%$ of the 16 adamantinomatous CP examined. These mutations were all somatic in origin as long as they were not found in genomic DNA from affected patients. Interestingly, these mutations are significantly more frequent in younger patients. The prevalence of CTNNB1 mutations in adamantinomatous CP observed in different series varies from $16 \%$ to $100 \%$ [9, $12,41]$. The majority of $C T N N B 1$ gene mutations affected serine or threonine phosphorylation sites encoded by exon 3 , which encodes the degradation targeting box of betacatenin. Accumulation of nuclear $\beta$-catenin protein results in enhanced transcriptional activity, as demonstrated in vitro for $C T N N B 1$ variants carrying similar mutations in exon 3 [42]. Furthermore, strong $\beta$-catenin expression has been demonstrated in immunohistochemical studies of the adamantinomatous subtype $[9,11,13]$ indicating reactivation of the Wnt signaling pathway, which is implicated in the development of several neoplasms including CP [41]. Indeed, recently, study using the primary human adamantinomatous $\mathrm{CP}$ cell cultures and small interfering RNA (siRNA) directed against the CTNNB1 gene showed that tumor cell migration was significantly reduced suggesting that activated Wnt signaling serves as a promoter of the epithelial migration machinery [43].

Based on bioinformatics analysis, we chose a panel of miRNAs which target the Wnt pathway in order to better understanding the role of these post-transcriptional regulators on Wnt signaling cascade. We demonstrated, for the first time, hyperexpression of miR-150 and underexpression of let-7a, miR-16, miR-15a, miR-23b, miR-24-2, miR-141,
miR-143, miR-145, and miR-449 in CP. In silico analysis demonstrated that miR-150, miR-23b, miR-24-2, miR-141, and miR-449 are regulators of CTNNB1 gene. All these miRNAs, but miR-150, might act as tumor suppressors. In normal conditions, miRNAs could bind with partial homology to CTNNB1 mRNA leading to mRNA translation inhibition, while binding with high homology would cause mRNA degradation. Thus, we postulated a putative connection between downregulation of tumor suppressive miRNAs and consequently the accumulation of $\beta$-catenin in the cytoplasm and nucleus, which would affect transcription of large number of Wnt targets during Wnt signaling in CP. Recently, it has been demonstrated in adrenal tumors that miR-15, miR-16, and miR-24-2 modulate Wnt4 (Wingless tipo 4) and mir-449 modulates Wisp2 (WNT1-inducible signaling pathway protein 2 , important players of $\mathrm{Wnt}$ signaling pathway [21]. On the other hand, we observed an overexpression of mir-150 in $\mathrm{CP}$, which in silico modulates adenomatous polyposis coli (APC); thus, mir-150 could be acting as an oncoMir. APC proteins have a role in $\beta$-catenin degradation, and mutations of the APC gene activate the Wnt pathway and lead to tumor formation [42]. Given the number of Wnt genes and their widely ranging functions, it is not surprising that mis-regulation of such an important pathway is involved in the genesis of many cancers, including craniopharyngioma.

To discover a putative association between the presence of CTNNB1 mutation and the severity of the disease, we studied the correlation of different variables such as age at the diagnosis, tumor size, and recurrence and the microRNA expression levels. We observed no association between the presence of CTNNB1 mutation and tumor size or recurrence of the disease, suggesting that the CTNNB1 mutation seems to be one among other mechanisms that might be involved in the formation of CP. Regarding miRNA expression, we observed no difference in the expression of each miRNA between children and adults. On the other hand, miR23a and miR24-2 were more expressed in patients with $\mathrm{CP}$ who underwent only one surgery than CP patients with two or more surgeries. More interestingly, miR-16 and miR-141 were underexpressed in $\mathrm{CP}$ patients presenting CTNNB1 mutation. Indeed, the majority of CTNNB1 non mutated CP (75\%) presented both miR-141 and miR-16 upregulated. These miRNA elevations could compensate for the lack of CTNNB1 mutation and serve to activate the Wnt pathway. Therefore, we suggest that at least two different defects could be involved in the $\mathrm{CP}$ pathogenesis and outcome: the presence of CTNNB1 mutations and/or the deregulation of the Wnt pathway by differential miRNA expression. Further studies are needed to predict miRNA target genes for either downregulated or upregulated miRNAs in CP. 
In conclusion, our findings indicate that the majority of patients with craniopharyngioma present endocrine disorders and hypothalamic injury, large tumors with invasion and compression of surrounding structures. All therapeutic standard of care did not allow tumor resection or growth control leading patients to undergo repetitive surgeries and to present high prevalence of hypopituitarism and diabetes insipidus. In addition, mutations or SNPs in pituitary transcription factors involved in Rathke's pouch and anterior pituitary development are unlikely to contribute to the adamantinomatous CP pathogenesis. Conversely, CTNNB1 gene mutation was observed in a high prevalence, confirming that this alteration is a hallmark of the adamantinomatous CP, mainly in children. Finally, we investigated, for the first time, the microRNA signature and its clinical significance in $\mathrm{CP}$; these data suggest the Wnt signaling pathway, via microRNA regulation, might be a mediator of $\mathrm{CP}$ tumorigenesis.

Acknowledgments The authors thank Wendy Turatti, Lucimara Bueno, Adriana Rossi, and Jose Roberto Silva for the technical support.

Disclosure statement The authors declare that they have no conflict of interest.

\section{References}

1. Karavitaki N et al (2006) Craniopharyngiomas. Endocr Rev 27 (4):371-397

2. Sarubi JC et al (2001) Clonal composition of human adamantinomatous craniopharyngiomas and somatic mutation analyses of the patched (PTCH), Gsalpha and Gi2alpha genes. Neurosci Lett 310(1):5-8

3. Rickert CH, Paulus W (2003) Lack of chromosomal imbalances in adamantinomatous and papillary craniopharyngiomas. J Neurol Neurosurg Psychiatry 74(2):260-261

4. Rienstein S et al (2003) Comparative genomic hybridization analysis of craniopharyngiomas. J Neurosurg 98(1):162-164

5. Nozaki M et al (1998) Rare occurrence of inactivating p53 gene mutations in primary non-astrocytic tumors of the central nervous system: reappraisal by yeast functional assay. Acta Neuropathol 95(3):291-296

6. Goldberg GM, Eshbaugh DE (1960) Squamous cell nests of the pituitary gland as related to the origin of craniopharyngiomas. A study of their presence in the newborn and infants up to age four. Arch Pathol 70:293-299

7. Prabhu VC, Brown HG (2005) The pathogenesis of craniopharyngiomas. Childs Nerv Syst 21(8-9):622-627

8. Takuma N et al (1998) Formation of Rathke's pouch requires dual induction from the diencephalon. Development 125(23):48354840

9. Buslei R et al (2005) Common mutations of beta-catenin in adamantinomatous craniopharyngiomas but not in other tumours originating from the sellar region. Acta Neuropathol 109(6):589597

10. Hassanein AM et al (2003) beta-Catenin is expressed aberrantly in tumors expressing shadow cells. Pilomatricoma, craniopharyngioma, and calcifying odontogenic cyst. Am J Clin Pathol 120(5):732-736
11. Kato K et al (2004) Possible linkage between specific histological structures and aberrant reactivation of the Wnt pathway in adamantinomatous craniopharyngioma. J Pathol 203(3):814-821

12. Sekine $\mathrm{S}$ et al (2002) Craniopharyngiomas of adamantinomatous type harbor beta-catenin gene mutations. Am J Pathol 161(6):1997-2001

13. Hofmann BM et al (2006) Nuclear beta-catenin accumulation as reliable marker for the differentiation between cystic craniopharyngiomas and rathke cleft cysts: a clinico-pathologic approach. Am J Surg Pathol 30(12):1595-1603

14. Logan CY, Nusse R (2004) The Wnt signaling pathway in development and disease. Annu Rev Cell Dev Biol 20:781-810

15. Cheng AM et al (2005) Antisense inhibition of human miRNAs and indications for an involvement of miRNA in cell growth and apoptosis. Nucleic Acids Res 33(4):1290-1297

16. Zhang B et al (2007) MicroRNAs as oncogenes and tumor suppressors. Dev Biol 302(1):1-12

17. Lee YS, Dutta A (2009) MicroRNAs in cancer. Annu Rev Pathol 4:199-227

18. Bottoni A et al (2007) Identification of differentially expressed microRNAs by microarray: a possible role for microRNA genes in pituitary adenomas. J Cell Physiol 210(2):370-377

19. Amaral FC et al (2009) MicroRNAs differentially expressed in ACTH-secreting pituitary tumors. J Clin Endocrinol Metab 94 (1):320-323

20. Bottoni A et al (2005) miR-15a and miR-16-1 down-regulation in pituitary adenomas. J Cell Physiol 204(1):280-285

21. Iliopoulos D et al (2009) MicroRNA signature of primary pigmented nodular adrenocortical disease: clinical correlations and regulation of Wnt signaling. Cancer Res 69(8):3278-3282

22. Cury ML et al (2009) Non-functioning pituitary adenomas: clinical feature, laboratorial and imaging assessment, therapeutic management and outcome. Arq Bras Endocrinol Metabol 53(1):31-39

23. Antonini SR et al (2001) Hesx 1 gene in midline cerebral defects. J Pediatr 139(5):754

24. Dattani MT et al (1998) Mutations in the homeobox gene HESX1/ Hesx 1 associated with septo-optic dysplasia in human and mouse. Nat Genet 19(2):125-133

25. Ohta K et al (1992) Mutations in the Pit-1 gene in children with combined pituitary hormone deficiency. Biochem Biophys Res Commun 189(2):851-855

26. Karavitaki $\mathrm{N}$ et al (2005) Craniopharyngiomas in children and adults: systematic analysis of 121 cases with long-term follow-up. Clin Endocrinol Oxf 62(4):397-409

27. Paja M et al (1995) Hypothalamic-pituitary dysfunction in patients with craniopharyngioma. Clin Endocrinol Oxf 42(5):467-473

28. Weiner HL et al (1994) Craniopharyngiomas: a clinicopathological analysis of factors predictive of recurrence and functional outcome. Neurosurgery 35(6):1001-1010, discussion 1010-1

29. Garre ML, Cama A (2007) Craniopharyngioma: modern concepts in pathogenesis and treatment. Curr Opin Pediatr 19(4):471-479

30. Roth CL, Gebhardt U, Muller HL (2010) Appetite-regulating hormone changes in patients with Craniopharyngioma. Obesity. doi:10.1038/oby.2010.80

31. Fahlbusch R et al (1999) Surgical treatment of craniopharyngiomas: experience with 168 patients. J Neurosurg 90(2):237-250

32. Adamson TE et al (1990) Correlation of clinical and pathological features in surgically treated craniopharyngiomas. J Neurosurg 73 (1):12-17

33. Olson LE et al (2006) Homeodomain-mediated beta-catenindependent switching events dictate cell-lineage determination. Cell 125(3):593-605

34. Li S et al (1990) Dwarf locus mutants lacking three pituitary cell types result from mutations in the POU-domain gene pit-1. Nature 347(6293):528-533

35. Gage PJ et al (1996) The Ames dwarf gene, df, is required early in pituitary ontogeny for the extinction of Rpx transcription and 
initiation of lineage-specific cell proliferation. Mol Endocrinol 10 (12):1570-1581

36. Sornson MW et al (1996) Pituitary lineage determination by the Prophet of Pit-1 homeodomain factor defective in Ames dwarfism. Nature 384(6607):327-333

37. Hermesz E, Mackem S, Mahon KA (1996) Rpx: a novel anteriorrestricted homeobox gene progressively activated in the prechordal plate, anterior neural plate and Rathke's pouch of the mouse embryo. Development 122(1):41-52

38. Mendonca BB et al (1999) Longitudinal hormonal and pituitary imaging changes in two females with combined pituitary hormone deficiency due to deletion of A301, G302 in the PROP1 gene. J Clin Endocrinol Metab 84(3):942-945

39. Voutetakis A et al (2004) Pituitary magnetic resonance imaging in 15 patients with Prop1 gene mutations: pituitary enlargement may originate from the intermediate lobe. J Clin Endocrinol Metab 89 (5):2200-2206

40. Dasen JS et al (2001) Temporal regulation of a paired-like homeodomain repressor/TLE corepressor complex and a related activator is required for pituitary organogenesis. Genes Dev 15 (23):3193-3207

41. Holsken A et al (2009) Target gene activation of the Wnt signaling pathway in nuclear beta-catenin accumulating cells of adamantinomatous craniopharyngiomas. Brain Pathol 19(3):357-364

42. Morin PJ et al (1997) Activation of beta-catenin-Tcf signaling in colon cancer by mutations in beta-catenin or APC. Science 275 (5307):1787-1790

43. Holsken A et al (2010) Tumour cell migration in adamantinomatous craniopharyngiomas is promoted by activated Wnt-signalling. Acta Neuropathol 119(5):631-639 